\title{
Reactive Thrombocythemia in Children with Iron Deficiency Anemia in Sulaimania province
}

\author{
Basil kadhim Abdullah Al odda* ${ }^{1}$, Zainab Basil Kadhim Al odda ${ }^{2}$, Ghada Basil Kadhim Al \\ odda $^{3}$, ZenaJameel Ahmed Hussein Al byatee ${ }^{4}$ \\ ${ }^{I}$ M.B.Ch.B, D.C.H, CABP pediatric (consultant subspecialty pediatric heamato-oncology)-Hiwa \\ teaching hospital-sulemania-Iraq. \\ ${ }^{2}$ Medical student, School of medicine, Amman University, Jordan. \\ ${ }^{3}$ sixth stage student, freshta secondary School, sulemania-Iraq. \\ ${ }^{4}$ teacher, Al-Jwahery primary school, Sulemania-Iraq.
}

*Corresponding Author: Basil kadhim Abdullah Al odda, M.B.Ch.B, D.C.H, CABP pediatric (consultant subspecialty pediatric heamato-oncology)-Hiwa teaching hospital-sulemania-Iraq

\begin{abstract}
Background: Thrombocytosis is a commonly encountered clinical scenario, with a large proportion of cases discovered incidentally. By far the most common cause of thrombocytosis in general medical populations is a reactive or secondary process.

Objective: With this background in mind the present work was planned to study the incidence of thrombocytosis in pediatric age group with iron deficiency anemia.

Patients and Methods: The study covered Children in the age group of 6 months to 12 years with thrombocytosis due to iron deficiency anemia. From EDTA blood, total and differential white cell counts were done by automated cell counter and counter checked by peripheral smear examination.

Results: By applying Chi-square test there is a significant association between age and thrombocytosis in the cases of IDA $(p<0.05)$ By applying Chi-square test there is a highly significant association between anemia, sex and thrombocytosis in the cases of IDA $(p<0.01)$.
\end{abstract}

Conclusion: From present study it is clearly seen association between thrombocytosis and iron deficiency anemia in pediatric age group.

Keywords: Children, Thrombocythemia, Iron deficiency anemia.

\section{INTRODUCTION}

Thrombocytosis in children can occur due to various causes leading to serious thromboembolic complications. Thrombocytosis is a commonly encountered clinical scenario, with a large proportion of cases discovered incidentally. By far the most common cause of thrombocytosis in general medical populations is a reactive or secondary process. From the non-infectious causes of secondary thrombocytosis, iron deficiency is a common one, since it is the single most common nutritional deficiency worldwide. ${ }^{(1,2)}$ The fact that thrombocytosis is more frequent in children up to 2 years of age is partly due to the higher incidence of iron deficiency in this age group. The mechanism for thrombocytosis in iron deficiency anemia remains unclear. ${ }^{(3,4)}$ With this back-ground in mind the present work was planned to study the incidence of thrombocytosis in pediatric age group with iron deficiency anemia.

\section{Patients And Methods}

The study was conducted in department of Pediatrics Hematology and Oncology of Hiwahospital, Sulaimania province, Kurdistan region, Iraq.

Over a period of two years from August 2010 to August 2012,the subjects who satisfied the following inclusion and exclusion criteria were enrolled in the study after obtaining informed consents from parents or legal guardians.

\section{Inclusion Criteria}

- Children with pallor detected among those attending out-patient departments for common childhood illnesses and diagnosed to be due to iron deficiency. 
- $\quad$ Children in the age group of 6 months to 12 years.

\section{Exclusion criteria}

- Children with age less than 6 months or more than 12 years.

- Children with chronic illnesses of prolonged duration.

- Children with anemia due to causes other than iron deficiency.

- Children with thrombocytosis due to causes other than iron deficiency anemia.

- Parents/ Lawful guardians not willing to give informed consent for the participation of the subject.

Subjects were enrolled over a period of two years. Parents of 100 children who satisfied inclusion and exclusion criteria agreed to enroll their wards.

\section{METHODOLOGY}

The selected patients were subjected to a detailed history and thorough clinical examination as per the forma attached. Relevant investigations were done as per individual case requirement. Their consent was recorded in the Informed Consent Document. The skin surface was wiped with iodine and then with spirit. The spirit was allowed to air dry and then using a 23 gauge needle, $10 \mathrm{ml}$ of venous blood was withdrawn and $2 \mathrm{ml}$ was preserved in an EDTA bulb, $4 \mathrm{ml}$ in a plain bulb, and the rest was centrifuged at a rate of $2500 \mathrm{rpm}$ for 5 to 10 minutes so that clear supernatant was achieved. This serum was separated and stored at -20 degree Celsius and used for subsequent analysis for Serum Ferritin. The samples in the EDTA and the plain bulbs were transported manually at room temperature to the laboratory and processed for $\mathrm{CBC}$ and Serum Iron, Serum TIBC respectively as soon as possible. From EDTA blood, total and differential white cell counts were done by automated cell counter and counter checked by peripheral smear examination.

\section{RESULTS}

Table1. Age and sex wise distribution of Thrombocytosis in cases of IDA

\begin{tabular}{|l|c|c|c|}
\hline Age in years & Male & Female & Total \\
\hline$<\mathbf{1}$ & $9 / 18(50 \%)$ & $2 / 12(16.66 \%)$ & $\mathbf{1 1 / 3 0 ( 3 6 . 6 6 \% )}$ \\
\hline $\mathbf{1 - 5}$ & $15 / 27(55.55 \%)$ & $16 / 25(64 \%)$ & $\mathbf{3 1 / 5 2}(\mathbf{5 9 . 6 1 \%})$ \\
\hline $\mathbf{5 - 1 0}$ & $3 / 3(100 \%)$ & $0 / 9$ & $\mathbf{3 / 1 2}(\mathbf{2 5 \%})$ \\
\hline$>\mathbf{1 0}$ & $0 / 6$ & 0 & $\mathbf{0 / 6}$ \\
\hline Total & $\mathbf{2 7 / 5 4}(\mathbf{5 0 \%})$ & $\mathbf{1 8 / 4 6}(\mathbf{3 9 . 1 \%})$ & $\mathbf{4 5 / 1 0 0}(\mathbf{4 5 \%})$ \\
\hline
\end{tabular}

Value of $\chi^{2}=4.12$, d.f. $=3, p>0.01$, significant.

By applying Chi-square test there is a significant association between ages and thrombocytosisin the cases of IDA $(p<0.01)$.

Table2. Status of Anemia in relation to Thrombocytosis

\begin{tabular}{|c|c|c|c|}
\hline \multirow[t]{2}{*}{ Anemia } & \multicolumn{3}{|c|}{ Thrombocytosis } \\
\hline & male & female & total \\
\hline Mild (Hb 10-11) $(n=6)$ & 0 & $6 / 6(100 \%)$ & $6 / 6(100 \%)$ \\
\hline Moderate $($ Hb 7-9.9) $(n=33)$ & $15 / 15(100 \%)$ & $0 / 18$ & $15 / 33(45.45 \%)$ \\
\hline $\operatorname{Severe}(H b<7)(n=61)$ & $12 / 36(33.33 \%)$ & $12 / 25(48 \%)$ & $24 / 61(39.3 \%)$ \\
\hline Total $(n=100)$ & $27 / 54(50 \%)$ & $18 / 46(39.1 \%)$ & $45 / 100(45 \%)$ \\
\hline
\end{tabular}

Value of $\chi^{2}=11.67$, d.f. $=2, p<0.01$, highly significant.

By applying Chi-square test there is a highly significant association between anemia, sex and thrombocytosis in the cases of IDA $(p<0.01)$.

\section{DISCUSSION}

The aim of the study was to evaluate the incidence/ prevalence of IDA and to find out the incidence of thrombocytosis in children with IDA in our region. No such specific study has been carried out in our country for children who are more prone for iron deficiency anemia.
Although there has been paucity of studies on secondary thrombocytosis due to iron deficiency anemia in the international literature, but there are various case reports implicating the association of thrombocytosis with iron deficiency anemia leading to cerebrovascular accidents.(5) 
Table3. Distribution of IDA according to age in various studies

\begin{tabular}{|l|l|l|l|l|l|}
\hline & No. of Cases (n) & $<\mathbf{1}$ year & $\mathbf{1 - 5}$ years & $\mathbf{5 - 1 0}$ years & $>$ 10 years \\
\hline Present Study $^{\text {Sharma et al }} \mathbf{( 3 )}^{(100}$ & 312 & 30 & 52 & 12 & 6 \\
\hline Dalal et al $^{(\mathbf{4}}$ & 40 & 200 & 22 & 39 & 51 \\
\hline Bhagoankar et al $^{(\mathbf{5})}$ & 50 & 18 & 7 & 15 & - \\
\hline
\end{tabular}

In the present study (2012), the cases of IDA are maximum in the age group of 1 to 5 years with 52 cases $(52 \%)$ while in the age group of more

Table4. Thrombocytosis according to age groups than 10 years; only 6 cases (6\%) are affected with iron deficiency.

\begin{tabular}{|c|c|c|c|c|c|}
\hline & No. of Cases (n) & < 1 year & 1-5 years & 5-10 years & $>10$ years \\
\hline Present Study & 100 & 11 & 31 & 3 & 0 \\
\hline Duzgun et al $^{(6)}$ & 102 & 10 & 27 & 3 & 0 \\
\hline
\end{tabular}

The above mentioned study had evaluated the age group from 4 months to 168 months, with only one patient aged 4 months while the rest were older than 6 months. In the present study the age group we looked at was 6 months to 12 years. In the study population, thrombocytosis due to iron deficiency anemia is seen mostly in the age group of $1-5$ years with 31 cases
$(68.88 \%)$ out of a total of 45 cases falling in this group. This is in concordance with the study of Duzgun et al who concluded that thrombocytosis due to IDA is less common over 61 months of age. In our study, only 3 cases of thrombocytosis due to IDA are seen in the age group of 5 to 10 years and no case is seen in the age group above 10 years.(6)

Table5. Severity of Anemia in relation to Thrombocytosis

\begin{tabular}{|l|c|c|c|}
\hline \multirow{2}{*}{ Anemia } & \multicolumn{3}{|c|}{ Thrombocytosis } \\
\cline { 2 - 4 } & Male & Female & Total \\
\hline Mild $($ Hb 10-11) $(\mathbf{n}=\mathbf{6})$ & $\mathbf{0}$ & $6 / 6(100 \%)$ & $\mathbf{6}(\mathbf{1 3 . 3 3 \%})$ \\
\hline Moderate $(\mathbf{H b} 7-9.9)(\mathbf{n}=\mathbf{3 3})$ & $15 / 15(100 \%)$ & $0 / 18$ & $\mathbf{1 5}(\mathbf{3 3 . 3 3 \%})$ \\
\hline Severe $(\mathbf{H b}<7)(\mathbf{n}=\mathbf{6 1})$ & $12(50 \%)$ & $12(50 \%)$ & $\mathbf{2 4}(\mathbf{5 3 . 5 4 \%})$ \\
\hline Total $(\mathbf{n}=\mathbf{1 0 0})$ & $\mathbf{2 7 / 5 4}(\mathbf{6 0 \%})$ & $\mathbf{1 8 / 4 6}(\mathbf{4 0} \%)$ & $\mathbf{4 5}(\mathbf{4 5 \%})$ \\
\hline
\end{tabular}

In analyzing the severity of anemia in relation to thrombocytosis, all the 6 cases with mild anemia have thrombocytosis while out of a total of 33 cases with moderate anemia, 15 cases $(45.45 \%)$ have thrombocytosis. Amongst 61 cases with severe anemia, 24 cases (39.3\%) suffer from thrombocytosis. On general physical examination of the subjects under study, pallor is the most consistent finding, seen in 94 cases (94\%), followed by glossitis in 12 cases (12\%). Nail changes are seen in 8 cases in the form of platynychia in 5 cases (5\%) and koilonychias in 3 cases (3\%). Knuckle pigmentation is seen in 7 cases $(7 \%)$. Tachycardia is seen in 9 cases $(9 \%)$ and tachypnea is seen in 3 cases (3\%). Amongst other positive findings on systemic examination, common finding is murmurs in 12 cases (flow murmurs in 9 cases and organic in 3 cases). Hepatomegaly is seen in 10 cases (10\%) while 4 cases $(4 \%)$ have palpable spleen.

\section{CONCLUSION}

From present study it is clearly seen association between thrombocytosis and iron deficiency anemia in pediatric age group. Though this study not clearly explains the Pathophysiology of thrombocytosis, our aim was to study their association with iron deficiency anemia particularly in pediatrics.

\section{ABBreViation}

EDTA: Ethylenediaminetetraacetic acid

IDA: Iron Deficiency Anemia

Ml: Milliliter

Rpm: Revolutions per minute

TIBC: Total Iron Binding Capacity

CBC: Complete Blood Count

\section{ACKNOWLEDGMENTS}

We gratefully acknowledge both patient and his family for allowing us to publish their case report.

\section{REFERENCES}

[1] McMillan JA, Oski FA, Lourie $G$ et al. Iron absorption from human milk, simulated human milk and proprietary formulas. Pediatrics 1977; 60: 896.

[2] Saarinen UM, Siimes MA, Dallman PR. Iron absorption in infants: high bioavailability of breast milk iron is indicated by the extrinsic tag method of iron absorption and by the concentration of serum ferritin. J Pediatr 1977; 91: 36 . 
Reactive Thrombocythemia in Children with Iron Deficiency Anemia in Sulaimania province

[3] Duzgun S, Yildirmak Y, Cetinkaya F. Neutrophilhypersegmentation and thrombocytosis in children with iron deficiency anemia. Turk J Pediatr2005; 47: 251-254.

[4] Poskitt, Elizabeth ME. Early history of iron deficiency anemia. British Journal of Haematology 2003; 122(4): 554-562.
[5] Hart, G.D. Description of blood and blood disorders before the advent of laboratory medicine. British Journal of Haematology 2001; 115, 719-728.

[6] Finch CA, Huebers HA. Iron metabolism. Clin Physiol Biochem 1986; 4: 5

Citation: Basil kadhim Abdullah Al odda et. al, "Reactive Thrombocythemia in Children with Iron Deficiency Anemia in Sulaimania province”, International Journal of Research Studies in Medical and Health Sciences. 2021; 6(1): 21-24. DOI: https://doi.org/ 10.22259/ijrsmhs.0601004

Copyright: (C) 2021 Basil kadhim Abdullah Al odda et. al, This is an open-access article distributed under the terms of the Creative Commons Attribution License, which permits unrestricted use, distribution, and reproduction in any medium, provided the original author and source are credited. 